ST. PAUL AND ST. BARNABAS DISPENSARY, UPPEPu EBURY-STREET, PIMLICO.

Mr. Morry, the resident medical officer, informs us :- "We usually treat diarrhoea (of which we have had a great number of cases, and all recovered, as follows:-A pill, containing one grain of calomel, and a quarter of a grain of opium, or two grains of calomel and half a grain of opium, to be taken directly; a mustard poultice to the abdomen; and, an hour after the pill, a draught, containing a scruple of aromatic confection in an ounce of cinnamon-water, to be repeated after each relaxation. Sometimes we give the chalk mixtmre instead.

"In six cases of choleraic diarrhoa the following treatment has been adopted, (four cases have recorered, and two are doing well.) The pill before named to be taken directly, and a mixture cortaining two drachms of dilute sulphuric acid to eight ounces of water, of which an ounce is given every two hours.

"Three cases of Asiatic cholera have occurred, all of which were preceded by diarrhoea, (neglected,) and not seen until in a state of collapse. Two of these were in clildren, one eight, the other five years old. During collapse small doses of calomel frequently repeated, and the acid mixture every half hour during the consecutive fever, were given. The former hod a mixture containing nitrate of potass and solution of acetate of ammonia, with an excess of ammonia. The patient died. The latter, during the consecutive fever, took five rrains of cillorate of potass in half an ounce of water, every half hour and recovered. The former, during the collapse, had small quantities of port-wine occasionally. The latter had no stimulant whatever. A woman, aged fifty-seven, during collapse, took a pill containing one grain of calomel and a quarter grain of opium, every second hour; and the acid mixture, with the aldition of compound spirit of sulphuric ether twenty minims ercry half hour. She recovered from the collapse, but died of the consecutive fever three days afterwards."

\section{EASTERN DISPENSARY,}

GREAT ALIE-STREET, WHTTECHAPEL.

Mr. Jomi C. Barry, resident medical officer, writes:"Up to this date (August 18th) I have had no real case of Asiatic cholera presenting itself to my notice. However, obstinate and severe diarrhcen, frequently accompanied with cramps, coldress of extremities, and vomiting, (in fact the ordinary disease usually termed English cholera, ) has been very prevalent in our district, the number of cases relieved since the 1st of August being 254.

"I have tried a great many formula, but find none answer so well in arresting pain and relaxation as the mixture prescribed by Dr. Munk, physician to onr institution, composed according to the printed instructions I have subjoined.

"Some few cases have come under my notice (the diarrhoea having been checked by this treatment) of coldness of extremities and pains of the stomach and bowels, in which I have been in the habit of prescribing the following-viz.: Sesquicarbonate of ammonia, five grains; tincture of opium, ten minims; camphor mixture, an ounce: mix for a draught, to be taken every four hours. I have also ordered a mustard cataplasm to the stomach and howels, with bottles of hot water to the feet; and if the patient has felt inclined for any nourishment, I have ordered brandy and arrowroot at intervals.

"Should any cases of real Asiatic cholera come under my notice, I shill have sreat pleasure in forwarding an account of the symptorns, treatment, \&c., for publication in THE LAXCET.

"I beg to enclose the printed instructions directed by Dr. Hunk to be issucd with his mixture

"Meclicine for Relaxulion or Looseness of the Bowels.Dcse for persons above fourteen years of age, three tablespoonfuls; dose for persons above seven and under fourteen years of age, two tablespoonfuls; dose for children above two ind nnder seven years of age, one tablespoonful; dose for children under two years of age, two teaspoonfuls. A dose to be taken immediately, and repeated every two or three hoursuntil medical advice can be obtained.

" I. B. - For the information of such medical practitioners as may subsequently have to treat the case, it is here stated that the proportions and ingredients of the mixture are as follow:-

"Compound chalk mixture, eleven drachms; compound cinnamon powder, six grains; tincture of catechu, forty-five minims; tincture of opitum, five minims. Mix."

(To be continuted.)

\section{ON THE}

\section{MODUS OPERANDI OF MERCURY IN THE CURE OF ASIATIC CHOLERA.}

\section{BY J. TAYLOR, EsQ., L.S.A}

AFTEr so many ephemeral productions have issued from the press on the nature and treatment of the epiciemic cholera, it would seem almost superfluous in me to attempt anything further on the subject, more especially as the disease and its treatment have been investigated by such able minds in every part of the British dominions - in fact, in every part of the world where the dire pestilence has prevailed.

Nevertheless, having witnessed the two last epidemics in this metropolis on an extensive scale, I may be peruitted to offer my mite, in addition to the observations of other writers; and having done this, if I shall have succeeded in bringing forth any new pathological fact which may tend hereafter to elucidate a point in the treatment of this disease, and enable us to handle our remedies with more confidence than we have hitherto done, and thus to reduce the heavy roortality by the preservation of only a few valuable lives, I shall indeed be ratified and amply rewarded.

It will be unnecessary here to investigate, with any degree of minuteness, the history and progress of choleia; its onward march in a northerly direction, from the shores of India along the great channels of luman intercourse; its invasion of any country almost always at a seaport, attacking fow people at first, and spreading thence in various directions; the comparative immunity from the disease of those places where the least communication is held with infected districts; and the remarkable fact, that wherever military cordons have been established in any country where cholera has prevailed, the disease has invariably made its way through every human barrier-military cordons being, in reality, the connecting links between one frontier and another. These facts, in my opinion, afford the strongest evidence that the disease, what ever may be its epidenic origin, is propagated by human intercourse, although the exact manner in which the materies morbi may be supposed to enter the system must, for the present, remain an open question. Nevertheless, there are strong grounds for believing that it is from the living, and not from the dead body, that the source of propagation is derived, and that the alimentary canal affords the materials. In support of this theory, numerous cases might be cited. One or two will suffice for the present occasion.

An intelligent and well-educated neighbour, an undertaker, informed me, during the prevalence of the epidemic cholera of 1832, that a number of men in his establishment, who were extensively employed from morning till nirght in burying the dead, were frequently compelled to carry without coffins the bodies of those who had died of cholera from an upper to a lower apartment, in consequence of the narromness of the staircase not permitting a cofin to be carried up; yet, notwithstanding this daily exposure in the worst infected districts, not a man so employed was sick from cholera during the whole season

Again, during the last epidemic of 1849 , whilst the terrorstricken inhabitants of thig district were wituessing with dismay the fearful ravages of the disease, a melancholy instance occurred, a few doors from my residence, which greatly tends to corroborate the plain and simple theory of Dr. Snow-viz., "That it is from the excretions of the alimentary canal being swallowed, or by some subtile process conveyed into the stomach and bowels," that the discase is propagated; but whether these materies morti are to be regarded as inorganic or organic, in the shape of a nucleated cell or vesicle, is a question which is probably left for the microseopist to solve. I will relate the circumstance as it occurred.

A family consisted of husband, wife, son, and danghter: the first, for a few days cluring the early part of July, had suffered from diarrhoea, of which he, like many others, took but little notice; on the night of the fourth day he was seized with cholera of the worst kind, and died on the fullowing day. At the same time the wife was seized, and on the following day she died also. Simultaneously the son and daughter were attacked; the son shared the same fate as his perents; the daughter, a little girl about ten years of age, rias remcred to another district, and recovered. The servant alone escaper, although she officiate as nurse to the whole of the family. The house in which this calamity occurred became deserted for about two years afterwards, and on the drains being examined, it was found that the privy had overflowed into the drain; from the drain the rats had made a communication into the well from which the water was supplied to the family for domestic 
purposes. The frightful mortality which befel the inhabitants of Albion-terrace, Wandsworth-road, occurred shortly after this period, where the water became contaminated from a similar source, and above twenty of the inmates perished. I need say no more; those who think with me will no doubt conclude that this short history will in itself preclude the necessity for any further comment.

Haring endeavoured to establish at least plausible reasons for belief in the communicability of cholera by means of human intercourse, and the source from which, for want of better evidence, such communicability may be supposed to emanate, $I$ shall now proceed to consider the disease pathologically.

A writer" on cholera, in 1832, says: "Reviewing the symptoms during life, and the appearance after death, it will be apparent that the stomach and small intestines form the primary seat of the disease." + This is manifestly true, and this local affection of the alimentary canal affords a sufficient explanation for all the consequenit general symptoms. The precursory diarrhoa-frequently the harbinger of an attack of cholera-is attended with little or no disturbance of the general health. The daily meals are taken with the usual relish; the ordinary business duties are performed with the usual alacrity; the individual imagines, nay, often insists, that a moderate purging is doing him good. He is thus taken off his guard, and after partaking of a hearty supper, retires to rest, little thinking, perhaps, that he will be disturbed between twelve and two o'clock in the morning by that overwhelming deluge from the stomach and bowels, so truly characteristic of the malignant cholera.

The serum of the blood being thus drained off by the copious and frequent liquid and colourless evacuations from the bowels by constant romiting, and by transudation through the skin, the blood becomes thick and viscid, and can no longer circulate with its usual velocity; severe cramps attack the muscles of the abdomen and extremities, collapse ensues, the hands, feet, and lips assume a mahogany colour, and soon become blue or purple, the secretion of urine is suspended, the pulse ceases at the wrist, the patient becomes asphyxiated, and ultimately comatose; and it, by the aid of either remedial means or constitutional strength, he should survive this condition, and reaction take place, the case will frequently emerge into what has been properly termed consecutive fever; and at this stage of the disease, and at this stage only, shall we find evidence of a morbid poison having entered the system. The effete matters which it was the office of the kidneys to eliminate from the system have been retained and absorbed, the blood is poisoned thereby, and fever, coma, and death are the consequences.

This detail of the symptoms as they follow in succession, from the invasion of the disease in the stomach and bowels, to the final close in death, will naturally lead to the consideration of post-mortem appearances, which, in fact, are precisely such as might have been anticipated. The three great cavities of the body show what might, à priori, be considered as unequivocal marks of extreme venous congestion; $¥$ and the mucous membrane of the intestines is found to be pulpy, soft, and thin, and in many instances as if it had been partly washed away.

The next and most important consideration will be the treatment. To those who draw hasty conclusions from appearances found on dissection, bloodletting would appear to be the appropriate remedy, although it is difficult to conceive how the abstraction of blood should enable that already thick and viscid filuid to circulate with greater facility. Yet Annesley, (p. 170,) states, in rather a serio-comic phrase, "That in nine cases out of ten it will prove successful, especially if the colour of the blood changes from black to red, if the pulse gets up, and the spasms be relieved." Jameson (p. 190) candidly says,-_" "In everycase it was difficult to get any blood to flow, and when any was obtained, it had a thick, jet-black, oily appearance, and would scarcely flow to the extent of a spoonful in half-an-hour; and would entirely cease as the patient fell into a state of collapse."

This exactly agrees with my own experience, although I am ready to admit that bloodletting may have been of service in many cases of cholera, not indeed as a remedy for the actual cholera symptoms, but as a means of relieving actual congestion of some organ which harl existed previously to the invision of the disease, and this relief to chronic inflammation or congestion would certainly place the patient in a more favourable condition for recovery, and thus enhance the value of a remedy which at one time obtained a wide-spread reputation.

* Pettigrew.
¥It is necessary here to avoid confounding the "post hoe" with the
"propter hoc." These post-mortem phenomena are probably owing to the
abstraction of the serum of the blood, whereby the red particles sulsside in the
yessels, and thus the appearance of congestion is produced.
yessels, and thus the appearance of congestion is produced.
Of medicines, the mhole materia melica has been ransacked; earth, air, and water have been called in to our aid; the animal, vegetable, and mineral lzingdoms have also done their part; every means that science and humanity cou d dictate, from the do-nothing method of a few orains of charcoal, to the heroic practice of scruple doses of calomel, (and eren transfusion,) have been tried, and each in its turn has been stated to have been successful. Not forgetting our old departed auxiliaries, musk, phosphorus, and cajeput oil, and the saline treatment; hot and cold water, cum multis aliis; I have tried them all, and with variable success. I may here remark that, in the epidemic of 1832 , phosphorus was raunted as a most potent and valuable remedy; in two cases where it was adninistered the patients became furiously maniacal, and they both died. It is, however, to Dr. Ayre, of Hull, that the medical profession is indebted for the scientific administration of mercury in Asiatic cholera, and my experience enables me to confirm its superiority far above any other remedy which has hitherto been recommended, my principal object in writing this paper being to point out the manner in which mercury produces its curative effects in this intractable disease. These opinions, it is true, may require the test of time to prove their truth or fallacy; but whatever may be the result, I can faithfully assert that they are reasonings from facts collected at the bedside, and are not the result of mere arm-chair lucubrations.

About the end of July and begimning of August, 1849, one or two circumstances occurred under my notice, beautifully illustrative of the proposition advanced by Sydenham, viz., "Whatever disease a person may be labouring nuder, duriug the prevalence of any epidemic, that disease will in some measure partake of the nature of the said epidemic."

I had encountered about this time a few cases of dysentery, but in so modified a form that the mucus discharge from the bowels, instead of exhibiting the usual colour, had the appearance and consistence of cream or blanc-mange. These cases all recovered. Other cases followed; and notwithstancing that they all occurred in cholera districts, not a single case passed into this disease. I was not long in observing that this modified dysentery was the salvation of my patients; that it was, in fact, antagonistic to the cholera. From this I was led to infer that if a remedy could be found capable of producing a dysenteric condition of the alimentary canal, we should so fir have established a principle in the treatment of a disease which had hitherto been little better than empirical. (I beg it to be undertood here that what is meant by a dysenteric condition is a bon $\hat{\alpha}$ fide subacute muco-enteritis.) The well-known effect of mercury on the bowels, its remarkable success in the hands of those who had administered it with undeviating perseverance, coupled with what I had observed in my own practice, served but to enhance its established superiority, and to afford a ready explanation of its modus operandi-viz., that by artificially inducing a subacute form of muco-enteritis, the superabundant discharge of serum is arrested, and an anta. gonizing barrier established to the further progress of the dis ease. It is highly probable that the reputution which tartarized antimony and iodine at one time enjoyed was due to a similarity of effect on mucous surfaces.

The mineral acids, of which the celebrated Austrian remedy is composed, probably produce their beneficial effects in the same manner. The method which I have pursued in administering mercury has not been dissimilar to that recommended by Dr. Ayre-viz., a grain of calomel* erery ten minutes, washed down with a little fresh cold spring water, drawn from a pure source. The bichloride has also been used in the form of injection; one grain, dissolved in eight ounces of distilled water, thrown up twice or thrice in the twenty-four hours. And as a substitute for the loss which the system had sustained, the following mixture was invariably prescribed in collapsed cases, to be taken with the mercury:-Chlorate of soda, phosphate of sold, of each half a drachm; spirit of nitric ether, one drachm; spring water, eight ounces: half a wineglassful to be taken every hour. These measures, assiduously applied by a good nurse, have certainly rescued many from impending death; and in almost all the successful cases recovery has been preceded by a mucus evacuation, frequently tinged with green, and this I have denominated the "mercurial stool," which, when once established, was generally indicative of a favourable termination. $t^{-}$The mercurial stool, then, having

* The quantity of calomel administered in rezorered cases varied from two to six drachms the latter quantity was certainly the maximum, and only
occlired in one instan $*$, where the patient persisted in taking the pills without my knowleage until the second day after reactiun had taken place. This wis the only case of severe ptyalism that occurret.

$t$ The only fatal drawback to this or any other plan of treatment being, that the patient will fretuently suceumb to the disease before the best directed remedies can produce their beneficial effects. 
fairly made its appearance, the mercury may be gradually withdrawn; and should consecutive fever follow, it must be combated by ordinary principles, according to the circumstances of the case. I have never found it of the least avail to torment the patient by friction with anodyne or stimulating liniments, for the relief of those severe cramps of the extremities, being fully satisfied they only interfere with that bodily tranguillity so essential to the patient's recovery.

I shall now conclude by recording my observations on opium, concerning which so much has been said and written. Its use appears to me to be limited to the precursory diarrhoe, and to the primary symptoms of cholera during the early stage of vomiting and purging, with excessive cramps, when the fingers have become shrunk and shrivelled, like those of a washerwoman, and before the hands and feet have assumed the mahogany, or blue colour; in short, before extreme collapse has set in, opium may be alministered freely, and with the happiest effects. From one to two grains, with the same of mercurial pill, for the first dose, and half the quantity of each every hour, for three successive doses, togetler with the before-mentioned saline mixture, and in some cases with the common chalk mixture, without any adjunct, (as this in many instances seemed to nauseate the stomach, ) assisted by a large sinapism to the epigastrium and abdomen, have frequently acted severally most beneficially, and restored the patient to comparative convalescence in the course of a few hours.

Whilst finishing this paper, I have been put completely hors de combat by the observation of my respected anatomical teacher, R. D. Grainger, Esq., who, on his late visit to the Wolverhampton Union, gave it as his opinion, "That there was no remedy for developed cholera." My opinion, however, is at variance with Mr. Grainger's assertion; but quite in accordance with the observation of Dr. Ayre, that mercury approaches as nearly to the character of a specific in cholera as quinine in intermittents. And the prevalence of the disease at present, as an epidemic, has again afforded me an opportunity of further testing its efficacy. The result of the treatment in nine cases (two deaths) of algid cholera, six of them quite collapsed and pulseless, has been such as greatly to increase my confidence in the mercurial treatment, and, at the same time, to surmount some of the difficulties in the way of its administration. The objections of children to the frequent repetition of powders, and the irksome task to Madam Nurse of mixing them and keeping to time, have been superseded by the following formula:Mercurial pill, half a drachm; purified sugar, half a drachm; sesquicarbonate of soda, two scruples; powdered gum Arabic, two drachms and a half; tincture of opium, ten drops; pure water sufficient to make three ounces: take half a teaspoonful every quarter of an hour, or every twenty minutes. This medi cine, like everything else, will be rejected by the stomach for several doses, but my motto has,been, "Spero et persevero," and I have not often been disappointed.

Having now thrown my mite into the scale in the canse of suffering humanity, those who have laboured with me in the same field will be best able to appreciate my exertions. "Etenim omnes artes, quæ ad humanitatem pertinent, habent quoddam commune vineulum et quasi cognatione quâdam inter se continentur."-Ciceronis Oratio pro Archia Poeta, p. 193.

Surrey-place, Old Fent-road, 1854.

\section{NOTE ON THE PROVISIONING OF ARMIES,}

IN RELATION TO THE

PRESEYT STATE OF OUR ARMY IN THE EAST,

By R. M. GLOVER, M.D., F.R.S.E.

GrEAT complaints have been made of the insufficient supply of food to our army in the East, cansed, it is said, in great part, by the want of transport. I am surprised that the attention of our military authorities has not been called to the great value of extract of meat, in such cases, both from its portability and its nutritive powers. There is no difficulty in preparing and preserving this substance, which affords, in very small comparative bulk, all the properties of the meat whence it is derived. Two or three ounces of it will make a pint and a half of excellent soup, which, with a ration of bread and some condiments, would make no bad meal for a soldier, when beef or mutton was not to be got; and for the sick its use would be invaluable. It must be altogether distinguished from the more bulky preserved meats, being, in fact, a watery extract, containing the quintessence of the nutritive powers of the meat. But the great value of this substance is its portability, containing as it does, or at least as there is every reason to think, the alimentary power of at least five or six times as much meat. Expense in such case should be no object, as the extract should be kept in reserve for emergencies

I called attention to this subject in an article of mine in a literary review some time ago. Liebig, I believe, originally made a proposition of the kind. On the plains of Buenos Ayres, where vast herds of cattle are slanghtered merely for the hides and tallow, might not a manufactory of this valuable substance be established? while the refuse of the animals could be turned into artificial guano and numerous chemical products.

I hope some of the medical officers who have interest with the Horse Guards may see this, and consider the proposition, for I cannot but think the matter of importance to the public service at the present time. If a large quantity of extract of meat had been sent ont with the army of the East, much misery might have been prevented; perhaps events of national moment might ere this have been achieved. I may add that it may be questioned whether the expense of the article might not be, to a great extent, made up by the facility of transport. August, 1815.

\section{CLINICAL AND CRITICAL CONTRIBUTIONS TO OBSTETRIC SCIENCE AND PRACTICE.}

\section{BY ROBERT BARNES, M.D. Lond.,}

MEMBER OF THE ROTIX COLLRGE OF PHYSICIANS, PHYSTCIAN-ACCOTCHETE TO WE POLITAY FRE HOSPITAL, LECTURER ON MIDWIFERY, FTC.

\section{APPENDIX TO A MEMOIR ON UTERINE POLYPUS: ITS NATURE,} EARLY DETECTION, AND TREATMENT.

\section{A CASE OF INTTA-UTERINE POLYPUS, UNDISCOVERED DURING} LTFE, CAUSING HZMNORRHAGE AND DEATH.

CASE 9.-Since my memoir "On Uterine Polypus" has been published, a case has occurred, offering a striking demonstration of the value of the rule in practice I ventured to enforce. I think it will be impossible to peruse the following facts without being struck with the conclusion, that a timely diagnosis of the nature of the case, and surgical intervention, might have rescued the patient.

In the night of the 3rd of August, my colleague, Dr。 Ramskill, was called to see a voung woman who was suffering from uterine hæmorrhage. The history of the case is briefly this : the patient was twenty-six years of age; she began to menstruate at the age of fourteen, and this furction was performed very regulariy until her marriage, eight months ago. From that time she has suffered almost perpetual hæmorrhage. A month ago, the flooding was so profuse that it was thought she had miscarried. Since then there have been slight occasional intermissions, but her health was deeply impaired. When Dr. Ramskill was called the hæmorrhage had returned. He observer' strong bearing-down, expulsive efforts. The patient died the same night in convulsions, evidently from loss of blood.

The body was examined by Dr. Ramskill on the following day. The organs were all healthy. There was no abdominal inflammation. The os uteri was healthy, but flaccid; it was filled with a fresh clot. There was also blood in the cavity of the uterus. The larger portion of the uterus, with a body adhering to the inner wall, was forwarded to me by Dr. Ramskill.

I subjected the parts to a careful examination. The walls of the uterus were dense, pale, somewhat thicker than natural, and the whole size of the organ somewhat larger than the normal unimpregnated womb. There was no tumour or other abnormal condition of the muscular wall, but attached to the inner surface near the fundus, and altogether enclosed within the cavity of the uterus, was a tumour of the size of a small walnnt. The tumour did not reach to the uterine neck. The mucous membrane of the cavity was stretched over it. It was comnected by a broad basis to the uterus, but would have admitted of isolation by ligature. The apex, or most projecting part, had undergone partial disintegration; it was a little broken up, softened, and had evidently quite recently been the source of hæmorrhage. Examined by the aid of the microscope, the substance was found to consist of nucleated fibres, the nuclei being larse and distinct. Portions, especially those tak $\in$ from near the apex, exhibited abundance of oily globules and numerous blood-globules. The structure of the tumour differed from that of the uterine wall in this respect only, that 